Article

\title{
Effects of Commonly Occurring Metal Ions on Hydroxyapatite Crystallization for Phosphorus Recovery from Wastewater
}

\author{
Hongliang Dai ${ }^{1,2} \mathbb{D}$, Xinwei Tan ${ }^{1}$, Hui Zhu ${ }^{1}$, Tongshuai Sun ${ }^{1}$ and Xingang Wang ${ }^{1, *}$ \\ 1 School of Environmental and Chemical Engineering, Jiangsu University of Science and Technology, \\ No. 2 Mengxi Road, Zhenjiang 212018, China; daihongliang103@163.com (H.D.); tc01143@163.com (X.T.); \\ 18252588451@163.com (H.Z.); 18252588460@163.com (T.S.) \\ 2 School of Energy and Environment, Southeast University, No. 2 Sipailou Road, Nanjing 210096, China \\ * Correspondence: hofs@just.edu.cn or hofs@163.com; Tel.: +86-0511-8563-5850
}

Received: 26 September 2018; Accepted: 7 November 2018; Published: 9 November 2018

\begin{abstract}
Hydroxyapatite crystallization for phosphorus recovery and removal from wastewater has attracted considerable attention for its potential economic and environmental benefits because hydroxyapatite can used as an effective compound fertilizer containing phosphorus $(\mathrm{P})$ for industrial and agricultural applications. As hydroxyapatite is obtained through precipitation and crystallization from wastewater, it is important to evaluate the roles of metal ions commonly found in wastewater during the hydroxyapatite crystallization process. Batch crystallization experiments were conducted to investigate the influence of $\mathrm{Mg}^{2+}, \mathrm{Fe}^{3+}, \mathrm{Cu}^{2+}$, and $\mathrm{Zn}^{2+}$ on $\mathrm{P}$ removal efficiency, and crystallized products were characterized using scanning electron microscopy as well as energy dispersive spectroscopy and X-ray diffraction. The presence of $\mathrm{Mg}^{2+}$ improved the phosphorus removal rate, but hydroxyapatite crystalline purity was reduced due to the co-precipitation of struvite and hydroxyapatite. $\mathrm{Fe}^{3+}$ and $\mathrm{Cu}^{2+}$ did not significantly affect the crystalline structure of hydroxyapatite because the two metal ions easily formed hydroxyl metal compounds with low solubility in alkaline solution, which is rarely involved directly in the hydroxyapatite crystallization process. There was strong background interference from $\mathrm{Zn}^{2+}$ on the hydroxyapatite $\mathrm{X}$-ray diffraction spectra, indicating that the crystallized products comprised a mixture of several amorphous substances. A comprehensive understanding of the effects of metal ions on hydroxyapatite crystallization will help improve the quality of hydroxyapatite products recovered from wastewater.
\end{abstract}

Keywords: hydroxyapatite; crystallization; metal ions; phosphorus recovery; wastewater

\section{Introduction}

Phosphorus $(\mathrm{P})$ is not only a limited and non-renewable mineral resource that makes a major contribution to agricultural and industrial development [1], but also the main element for causing water eutrophication $[2,3]$. With the decreasing availability of $P$ resources and increasing demand for water environmental quality, the recovery and removal of $P$ from wastewater have drawn great attention [4-6]. Urban domestic sewage contains abundant P; therefore, $15-20 \%$ of the world's P demand is theoretically satisfied by recovering and recycling $\mathrm{P}$ from wastewater [7]. The recovery of $\mathrm{P}$ from sewage can prevent eutrophication in water bodies, and recycling P resources carries economic and environmental benefits [2-10].

Currently, several technologies have been applied to $\mathrm{P}$ removal and recovery from wastewater $[9,11,12]$. One approach is the crystallization of $\mathrm{P}$ via the formation of struvite (or magnesium ammonium phosphate (MAP), $\left.\mathrm{MgNH}_{4} \mathrm{PO}_{4}\right)$ and hydroxyapatite $\left(\mathrm{HAP}, \mathrm{Ca}_{5}\left(\mathrm{PO}_{4}\right)_{3} \mathrm{OH}\right)$, 
which is economical and efficient, providing effective P recovery and high-quality crystallization products $[2,10,13,14]$. MAP crystallization can remove $\mathrm{P}$ and ammonia nitrogen simultaneously and is often used to recover nutrients from anaerobic digestion supernatant, pig wastewater, landfill leachate, and urine because it requires a high ammonia nitrogen concentration and high $\mathrm{pH}$ [15-17]. MAP crystallization is unsuitable for P recovery from municipal sewage because the concentration of ammonia nitrogen in municipal sewage is too low. However, HAP crystallization has a wide range of applications for treating P-containing wastewater at different concentrations and is especially suitable for the recovery of $P$ from anaerobic sedimentation tank effluent $(\sim 20 \mathrm{mg} / \mathrm{L})$ during the enhanced biological P removal (EBPR) process $[2,10]$.

HAP is a sparingly soluble salt $\left(\mathrm{Ksp}=2.35 \times 10^{-59}, 25^{\circ} \mathrm{C}\right)$ [18]. Theoretically, the principal chemical reaction for the formation of HAP is based on the following reaction:

$$
5 \mathrm{Ca}^{2+}+3 \mathrm{PO}_{4}{ }^{3-}+\mathrm{OH}^{-} \rightarrow \mathrm{Ca}_{5}\left(\mathrm{PO}_{4}\right)_{3} \mathrm{OH} \downarrow
$$

As shown in Equation (1), the crystallization process is strongly dependent on $\mathrm{pH}$ and the molar ratio of calcium (Ca)/ $\mathrm{P}$ [19]. Therefore, the $\mathrm{pH}$ and $\mathrm{Ca} / \mathrm{P}$ level of the solution are frequently employed to investigate HAP crystallization behavior [10]. The HAP crystallization process includes nucleation and crystal growth, which are affected by physicochemical factors such as $\mathrm{pH}$, supersaturation, $\mathrm{Ca} / \mathrm{P}$, temperature, mixing, and impurity ions. However, few studies have focused on the influences of metal ions on HAP crystallization. Municipal sewage has a wide range of sources and complex components [20]. There are many kinds of metal ions in such sewage, which may affect the process of phosphorus recovery from sewage by HAP crystallization. Therefore, it is important to study the mechanism of P recovery from wastewater by HAP crystallization in the presence of typical metal ions.

The $\mathrm{P}$ crystallization process includes nucleation and crystal growth processes affected by various factors such as the $\mathrm{pH}$, supersaturation ratio, temperature, and mixing, and by the existence of foreign ions [21]. Among these factors, few studies have focused on the influences of foreign ions on the $P$ crystallization process [22-26]. Madsen [24] investigated the inhibition behavior of $\mathrm{Cu}^{2+}$ and $\mathrm{Zn}^{2+}$ on crystal growth and the morphology of brushite $\left(\mathrm{CaHPO}_{4} \cdot 2 \mathrm{H}_{2} \mathrm{O}\right)$, and the results showed that both two metal ions demonstrated strong inhibitory effects on the crystallization of brushite. Muryanto and Bayuseno [25] found that both $\mathrm{Zn}^{2+}$ and $\mathrm{Cu}^{2+}$ inhibited struvite crystallization, with $\mathrm{Zn}^{2+}$ acting as a more effective antiscalant for struvite control. Yan and Shih [21] quantitatively evaluated the effects of $\mathrm{Ca}^{2+}$ and $\mathrm{Fe}^{3+}$ on struvite crystallization, and the results indicated that both $\mathrm{Ca}^{2+}$ and $\mathrm{Fe}^{3+}$ significantly inhibited the formation of struvite crystals and modified the needle-like struvite into irregular shapes. In our previous study, $\mathrm{Fe}^{3+}$ and $\mathrm{Cu}^{2+}$ increased the metastable zone width of HAP crystallization due to the adsorption of these impurity ions on the crystal surface, resulting in an increase in the energy level required for crystal product precipitation, effectively creating an energy barrier for crystallization [26].

Previous studies have focused mainly on identifying the characteristics of struvite and brushite products in the presence of metal ions, with less research on the phase composition and structure of HAP precipitates. In this study, we explored the optimal initial $\mathrm{pH}$ and $\mathrm{Ca} / \mathrm{P}$ ratio for HAP crystallization, and four metal ions $\left(\mathrm{Mg}^{2+}, \mathrm{Fe}^{3+}, \mathrm{Cu}^{2+}\right.$, and $\left.\mathrm{Zn}^{2+}\right)$ common in municipal sewage were selected to observe their effects on HAP crystallization at different concentrations. The results of this study will improve the current understanding of the HAP crystallization mechanism and provide a promising approach for the effective recovery of quality HAP products from wastewater as a renewable nutrient resource.

\section{Materials and Methods}

\subsection{Experimental Apparatus and Design}

$P$ recovery in the form of HAP crystallization from anaerobic supernatant of the Enhanced Biological Phosphorus Removal (EBPR) process was performed in a batch beaker. The temperature 
and stirring rate of the reaction system were controlled using a digital magnetic stirrer (LUXI 85-2W, Shanghai Luxi Industrial Co., Ltd., Shanghai, China) with a heating function. The Oxidation-Reduction Potential (ORP)/pH of the reaction system was measured using a pH meter (YSI Pro Plus, YSI Co. Ltd., Yellow Springs, OH, USA). The stirring rate and temperature were controlled at $200 \mathrm{rpm}$ and $23^{\circ} \mathrm{C}$, respectively. The reaction system was agitated for $20 \mathrm{~min}$, and then the solutions was precipitated for $2 \mathrm{~h}$, after which the precipitates were filtrated through 0.45- $\mu$ m filters (Millipore HAWP01300, MA, USA). The precipitates were dried in the drying oven with a temperature of $65{ }^{\circ} \mathrm{C}$ for $20 \mathrm{~h}$ before the subsequent characteristic analysis [3,8]. The liquor samples were also collected for the P removal efficiency in the form of HAP.

The chemical reagents used in the experiment were of analytical grade. Calcium chloride $\left(\mathrm{CaCl}_{2}\right)$, and potassium dihydrogen phosphate $\left(\mathrm{KH}_{2} \mathrm{PO}_{4}\right)$ were selected to produce HAP precipitation. In the experiment, $100 \mathrm{~mL}$ stock solutions of $\mathrm{CaCl}_{2}(200 \mathrm{mg} / \mathrm{L})$ and $\mathrm{KH}_{2} \mathrm{PO}_{4}(100 \mathrm{mg} / \mathrm{L})$ were agitated in a $1000 \mathrm{~mL}$ beaker. The chemical reagents were dissolved in distilled water to prepare stock solutions at a concentration of $0.1 \mathrm{M}$. To determine the influence of $\mathrm{pH}$, the following $\mathrm{pH}$ values were evaluated: 7.0, 7.5, 8.0, 8.5, 9.0, 9.5, 10.0, 10.5, and 11.0. $1 \mathrm{M} \mathrm{NaOH}$ solution was added to adjust the mixture solution $\mathrm{pH}$ to the designated values. Molar $\mathrm{Ca} / \mathrm{P}$ ratios of 1:2, 1:1, 1.67:1, and 2:1 were assessed, which have been suggested as HAP crystallization conditions based on a variety of wastewater-derived sources. The changes in phosphorus removal efficiency over $90 \mathrm{~min}$ with time were investigated under different molar ratios of $\mathrm{Ca} / \mathrm{P} . \mathrm{MgCl}_{2} \cdot 6 \mathrm{H}_{2} \mathrm{O}, \mathrm{FeCl}_{3}, \mathrm{CuCl}_{2} \cdot 2 \mathrm{H}_{2} \mathrm{O}$, and $\mathrm{ZnCl}_{2}$ were used to investigate the influences of typical metal ions on HAP crystallization. For the metal ion influence experiments, the dosages of four metal ions $\left(\mathrm{Mg}^{2+}, \mathrm{Fe}^{3+}, \mathrm{Cu}^{2+}\right.$, and $\left.\mathrm{Zn}^{2+}\right)$ were all designated as $0,5,10,15,20$, and $25 \mathrm{mg} / \mathrm{L}$ at the optimized $\mathrm{pH}$ and $\mathrm{Ca} / \mathrm{P}$ ratio.

P-containing wastewater was the simulated anaerobic supernatant of the enhanced biological phosphorus removal (EBPR) process (an anaerobic-anoxic/nitrifying two sludge process) previously established by our group [3]. The detailed components of wastewater used in this experiment were as follows: chemical oxygen demand (COD) of $84.2 \pm 4.3 \mathrm{mg} / \mathrm{L}\left(\mathrm{CH}_{3} \mathrm{COONa}\right), \mathrm{NH}_{4}{ }^{+}-\mathrm{N}$ of $36.5 \pm 2.2 \mathrm{mg} / \mathrm{L}$ $\left(\mathrm{NH}_{4} \mathrm{Cl}\right), \mathrm{PO}_{4}{ }^{3-}-\mathrm{P}$ of $21.2 \pm 1.1 \mathrm{mg} / \mathrm{L}\left(\mathrm{KH}_{2} \mathrm{PO}_{4}\right)$, and alkalinity of $312 \pm 25 \mathrm{mg} / \mathrm{L}\left(\mathrm{NaHCO}_{3}\right)$.

\subsection{Analytical Methods}

The P concentrations in the sample solution were measured using UV spectrophotometry at 700 $\mathrm{nm}$ based on the molybdenum-blue ascorbic acid method [27]. The concentrations of $\mathrm{Mg}^{2+}, \mathrm{Fe}^{3+}, \mathrm{Cu}^{2+}$, and $\mathrm{Zn}^{2+}$ were determined using an atomic absorption spectrometer (PerkinElmer AAS, Waltham Mass, MA, USA) in an air acetylene flame. The crystallized products were ground into powder using an agate mortar before the structure analysis. The morphology and relative content of the components of the crystallized products were determined using scanning electron micrography (SEM) with energy-dispersive spectrometry (EDS) (Hitach S-4800, Ibaraki, Japan). An X-ray diffraction analysis (XRD) for the product structure was carried out utilizing a D8 ADVANCE diffractometer (Bruker AXS, Karlsruhe, Germany) with diffraction patterns in step sizes of $0.02^{\circ}$, ranging from $10^{\circ}$ to $65^{\circ}$ at a $2 \theta$ angle.

\section{Results and Discussion}

\subsection{Effects of Ph on HAP Crystallization}

$\mathrm{pH}$ is a crucial factor for the HAP crystallization process. HAP crystallization cannot occur spontaneously at low $\mathrm{pH}$ due to the low saturation of the reaction system [19]. In contrast, a high-pH solution may be supersaturated, such that homogeneous precipitation can occur easily, which is not conducive to $\mathrm{P}$ recovery [26]. The anaerobic supernatant in the EBPR process contains abundant $\mathrm{P}$ but is lower in $\mathrm{pH}$ than the optimal value for HAP formation [10]. Therefore, it is necessary to optimize the $\mathrm{pH}$ of the reaction system for $\mathrm{P}$ recovery in the form of HAP. The effects of $\mathrm{pH}$ on $\mathrm{P}$ removal by HAP crystallization at an initial Ca/P molar ratio of 1.67 are shown in Figure 1 . As the $\mathrm{pH}$ increased from 7.0 to 11.0 , the $\mathrm{P}$ removal efficiency exhibited two stages. In the first stage, as the $\mathrm{pH}$ increased 
from 7.0 to 9.5 , the residual $\mathrm{P}$ concentration decreased to $0.902 \mathrm{mg} / \mathrm{L}$ at a $\mathrm{P}$ removal efficiency of 95.15\%. The most rapid increase in $\mathrm{P}$ crystal products occurred at $\mathrm{pH} 8-9$, at a rate of $15 \%$ per 0.5 increase in $\mathrm{pH}$. During the second stage, as the $\mathrm{pH}$ increased from 9.5 to 11.0, the P removal efficiency was relatively stable. The residual P concentration decreased by only $0.414 \mathrm{mg} / \mathrm{L}$, and the P removal efficiency increased from 95.15 to $95.66 \%$. The maximum $\mathrm{P}$ removal efficiency was $97.73 \%$ at $\mathrm{pH} 10.0$, and the residual P content was $0.454 \mathrm{mg} / \mathrm{L}$, which was lower than the first-class A standard $(0.5 \mathrm{mg} / \mathrm{L})$ set by the Discharge Standard of Pollutants for Urban Wastewater Treatment Plant (GB 18918-2002). The main reason for the observed $\mathrm{pH}$ effects on $\mathrm{P}$ removal efficiency was the presence of different forms of dissolved phosphate in the solution, including $\mathrm{PO}_{4}{ }^{3-}, \mathrm{HPO}_{4}{ }^{2-}, \mathrm{H}_{2} \mathrm{PO}_{4}{ }^{2-}$, and $\mathrm{H}_{3} \mathrm{PO}_{4}$ [28]. The equilibrium relationships of these phosphates in water were as follows:

$$
\begin{aligned}
\mathrm{H}_{3} \mathrm{PO}_{4} & \leftrightarrow \mathrm{H}_{2} \mathrm{PO}_{4}{ }^{-}+\mathrm{H}^{+} \mathrm{pKa} 1=2.12 \\
\mathrm{H}_{2} \mathrm{PO}_{4}{ }^{-} & \leftrightarrow \mathrm{HPO}_{4}{ }^{2-}+\mathrm{H}^{+} \mathrm{pKa} 2=7.21 \\
\mathrm{HPO}_{4}{ }^{2-} & \leftrightarrow \mathrm{PO}_{4}{ }^{3-}+\mathrm{H}^{+} \mathrm{pKa} 3=12.36
\end{aligned}
$$

At a low $\mathrm{pH}$, the content of $\mathrm{PO}_{4}{ }^{3-}$, as a product of the third-order ionization reaction, was lower than that of $\mathrm{H}_{2} \mathrm{PO}_{4}{ }^{-}$, the first-order ionization product. As the $\mathrm{pH}$ increased, the proportion of $\mathrm{PO}_{4}{ }^{3-}$ increased rapidly, and HAP formation was promoted, leading to an increase in P-removal efficiency. However, $\mathrm{Ca}^{2+}$ in solution readily forms $\mathrm{Ca}(\mathrm{OH})_{2}$ and $\mathrm{CaCO}_{3}$ precipitate at a high $\mathrm{pH}$; this process directly reduced the concentration of $\mathrm{Ca}^{2+}$ in solution and indirectly affected the crystallization reaction. Considering the $\mathrm{P}$ removal rate and recovery performance of the crystallized products, $\mathrm{pH} 9$ was selected as the best condition for the reaction system in subsequent experiments.

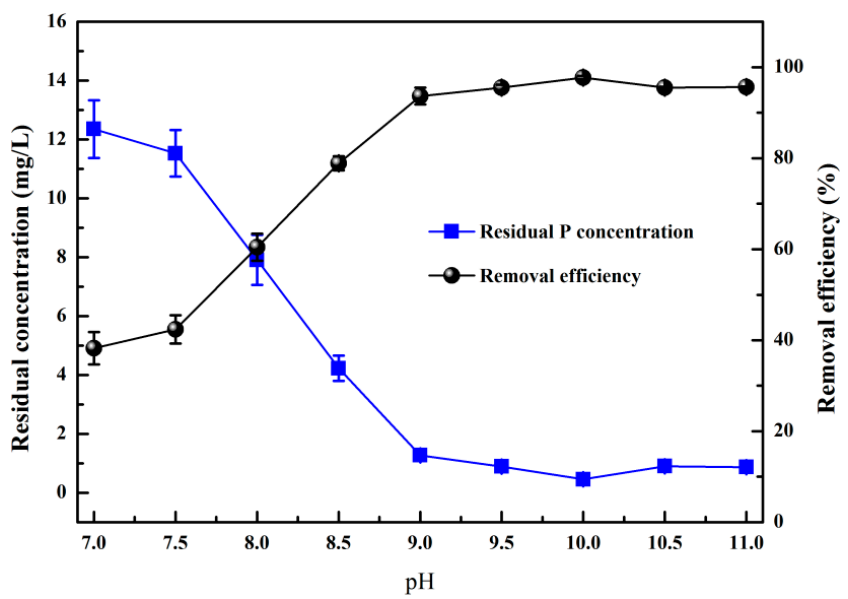

Figure 1. Effect of $\mathrm{pH}$ on phosphorus removal by HAP (Hydroxyapatite) crystallization.

\subsection{Effects of $\mathrm{Ca} / \mathrm{P}$ on HAP Crystallization}

In the solution of different $\mathrm{Ca} / \mathrm{P}$ for HAP crystallization, the precursors DCPD (dicalcium phosphate dihydrate, $\mathrm{CaHPO}_{4} \cdot 2 \mathrm{H}_{2} \mathrm{O}$ ), OCP (octacalcium phosphate, $\mathrm{Ca}_{4} \mathrm{H}\left(\mathrm{PO}_{4}\right)_{3} \cdot 2.5 \mathrm{H}_{2} \mathrm{O}$ ), and ACP (amorphous calciumphosphate, $\left.\mathrm{Ca}_{3}\left(\mathrm{PO}_{4}\right)_{2} \cdot \mathrm{xH}_{2} \mathrm{O}\right)$ formed first, and thermodynamically stable HAP was then formed through a series of material structure transformations $[10,19]$. To investigate the effects of $\mathrm{Ca}^{2+}$ concentration on the $\mathrm{P}$ removal efficiency, different concentrations of $\mathrm{CaCl}_{2}$ solution were added simultaneously to alter the $\mathrm{Ca} / \mathrm{P}$ ratio at $\mathrm{pH}$ 9. As shown in Figure $2 \mathrm{a}$, as the $\mathrm{Ca} / \mathrm{P}$ ratio increased, the $\mathrm{P}$ concentration decreased rapidly in the reaction system. When the reaction time was $90 \mathrm{~min}$, the concentration of phosphorus decreased from $20.3 \mathrm{mg} / \mathrm{L}$ to $8.32,4.56,1.32$, and $1.09 \mathrm{mg} / \mathrm{L} \mathrm{at} \mathrm{Ca/P}$ ratios of 1:2, 1:1, 1.67:1, and 2:1, respectively, with $P$ removal efficiency of $58.97 \%, 77.63 \%, 93.25 \%$, and $95.59 \%$, respectively (Figure $2 \mathrm{~b}$ ). When the $\mathrm{Ca} / \mathrm{P}$ molar ratio was greater than 1.67 , the excessive Ca concentration in the solution $(\mathrm{Ca} / \mathrm{P}$ ratio $=2.0)$ did not significantly increase the $\mathrm{P}$ removal efficiency. 
$\mathrm{CaCO}_{3}$ precipitation can occur via the addition of high concentrations of $\mathrm{Ca}^{2+}$ in an alkaline environment, permitting easy $\mathrm{Ca}^{2+}$ loss and a waste of chemicals [3]. P removal occurred mainly during the first $35 \mathrm{~min}$ of the reaction, and the P removal efficiency did not increase significantly after 35 min (Figure 2a). Therefore, the $\mathrm{Ca} / \mathrm{P}$ ratio was set to 2 and the reaction time to $35 \mathrm{~min}$ for subsequent experiments.
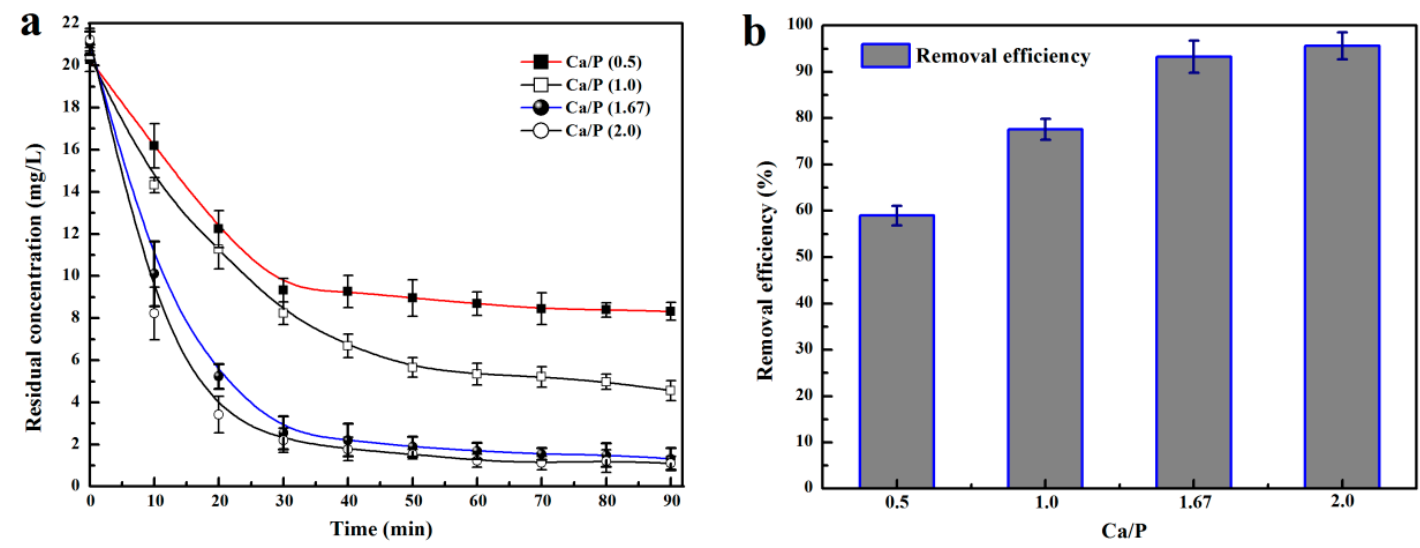

Figure 2. The effects of $\mathrm{Ca} / \mathrm{P}$ molar ratios on phosphorus removal by HAP crystallization.

\subsection{Effects of Metal Ions on the HAP Crystallization}

Metal ions in wastewater can have important effects on the physicochemical characteristics of HAP crystallization for P recovery. Several recent studies have investigated the properties of struvite crystallization in the presence of cationic and anionic impurities and found that these impurities can change the morphology and composition of crystallized products [21,25,29,30]. However, the effects of metal ions on HAP crystallization for P recovery have only been reported rarely. The effects of different concentrations of four metal ions $\left(\mathrm{Mg}^{2+}, \mathrm{Fe}^{3+}, \mathrm{Cu}^{2+}\right.$, and $\left.\mathrm{Zn}^{2+}\right)$ on the efficiency of $\mathrm{P}$ removal by $\mathrm{HAP}$ at $\mathrm{pH} 9.0$ and a $\mathrm{Ca} / \mathrm{P}$ ratio of 2.0 are shown in Figure 3.
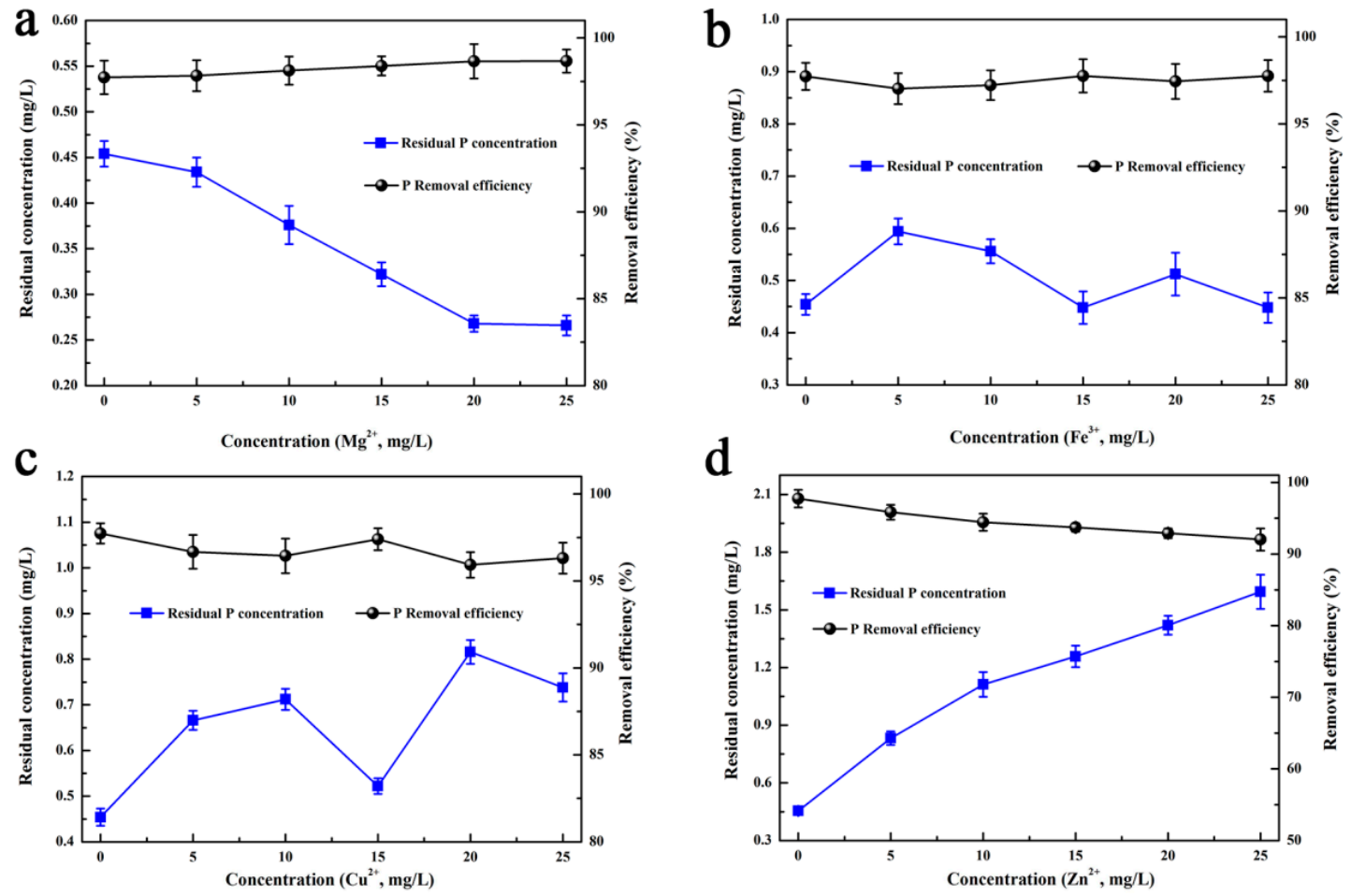

Figure 3. Effects of metal ions on the efficiency of phosphorus removal by HAP crystallization, (a) $\mathrm{Mg}^{2+}$; (b) $\mathrm{Fe}^{3+}$; (c) $\mathrm{Cu}^{2+}$; (d) $\mathrm{Zn}^{2+}$. 
As shown in Figure 3a, the residual P concentration decreased from 0.45 to 0.27 as the $\mathrm{Mg}^{2+}$ concentration increased from 0 to $25 \mathrm{mg} / \mathrm{L}$. Thus, the addition of $\mathrm{Mg}^{2+}$ contributed to the P removal rate (by $\sim 1 \%$ ), because the presence of $\mathrm{PO}_{4}{ }^{3-}, \mathrm{NH}_{4}{ }^{+}$, and $\mathrm{Mg}^{2+}$ in the reaction system made it possible to form MAP, in turn favoring P removal. In contrast, the precipitation of $\mathrm{Mg}^{2+}$ in the form of $\mathrm{Mg}(\mathrm{OH})_{2}$ consumed the alkalinity of the solution, making it unsuitable for HAP crystallization under the theoretical optimum $\mathrm{pH}$ condition; this phenomenon led to a decrease in the $\mathrm{P}$ removal efficiency. These conditions altered the residual $\mathrm{P}$ concentration and $\mathrm{P}$ crystallization rate in the reaction system.

The solubility of $\mathrm{Fe}^{3+}$ in water is limited, and its concentration less than $10 \mathrm{mg} / \mathrm{L}$ does not interfere with the chemical properties and functions of the solution [21]. Therefore, a wide range of $\mathrm{Fe}^{3+}$ concentration $(0-25 \mathrm{mg} / \mathrm{L})$ was chosen to study the role of $\mathrm{Fe}^{3+}$ in the crystallization of HAP. As shown in Figure $3 b$, the addition of $\mathrm{Fe}^{3+}$ did not significantly affect $\mathrm{P}$ removal from the solution, and the residual $\mathrm{P}$ concentration decreased only slightly as the $\mathrm{Fe}^{3+}$ concentration increased from 5 to $25 \mathrm{mg} / \mathrm{L}$. Previous studies have shown that $\mathrm{Fe}^{3+}$ exists mainly in the form of polyhydroxyl complexes in alkaline solution environments, where it co-precipitates with phosphate, mainly as ferric phosphate and ferric hydroxide. These complexes adsorb phosphate from wastewater to some extent, resulting in a reduction in the $\mathrm{P}$ concentration in the solution [21].

$\mathrm{Cu}^{2+}$ and $\mathrm{Zn}^{2+}$ were selected because the two metal ions are usually present in municipal sewage and piggery wastewater, and previous found that both $\mathrm{Cu}^{2+}$ and $\mathrm{Zn}^{2+}$ demonstrated strong inhibitory effects on the crystallization of phosphate minerals such as brushite $\left(\mathrm{CaHPO}_{4} \cdot 2 \mathrm{H}_{2} \mathrm{O}\right)$ [24] . Muryanto and Bayuseno [25] investigated struvite crystallization with interference from $\mathrm{Cu}^{2+}$ and $\mathrm{Zn}^{2+}$ and found that both ions can inhibit struvite crystallization and that $\mathrm{Zn}^{2+}$ was a more effective antiscalant for struvite crystallization than $\mathrm{Cu}^{2+}$. As shown in Figure $3 c, d$, the P removal efficiency could be inhibited by the presence of $\mathrm{Cu}^{2+}$ and $\mathrm{Zn}^{2+}$, which was similar to the results presented in Muryanto and Bayuseno's study [25] for MAP crystallization. The P removal efficiency decreased from 97.85 to $95.35 \%$ and from 97.73 to $92.03 \%$ as the $\mathrm{Cu}^{2+}$ and $\mathrm{Zn}^{2+}$ concentrations increased from 0 to $25 \mathrm{mg} / \mathrm{L}$, respectively, presumably due to the additive adsorption of molecules or ions onto the crystal surfaces [25]. In contrast, $\mathrm{Cu}^{2+}$ and $\mathrm{Zn}^{2+}$ can form metal hydroxides in alkaline solution, buffering the alkalinity of the reaction system and leading to a decrease in the P removal efficiency. $\mathrm{Zn}^{2+}$ inhibited the $\mathrm{P}$ removal efficiency more strongly than $\mathrm{Cu}^{2+}$ did because $\mathrm{Zn}^{2+}$ is an amphoteric metal, whose form in solution is greatly influenced by $\mathrm{pH}$. In an alkaline solution containing phosphate, $\mathrm{Zn}^{2+}$ produces the following chemical reactions:

$$
\begin{gathered}
3 \mathrm{Zn}^{2+}+2 \mathrm{PO}_{4}{ }^{3-} \rightarrow \mathrm{Zn}_{3}\left(\mathrm{PO}_{4}\right)_{2} \downarrow \mathrm{K}_{\mathrm{sp}}=9.1 \times 10^{-31} \\
\mathrm{Zn}^{2+}+2 \mathrm{OH}^{-} \rightarrow \mathrm{Zn}(\mathrm{OH})_{2} \downarrow \mathrm{K}_{\mathrm{sp}}=3.1 \times 10^{-17}
\end{gathered}
$$

$\mathrm{Zn}(\mathrm{OH})_{2}$ is an amphoteric hydroxide, and its solubility is related to $\mathrm{pH}$ value (Figure 4). When the $\mathrm{pH}$ is lower than $8, \mathrm{Zn}^{2+}$ exists mainly in the form of $\mathrm{Zn}_{3}\left(\mathrm{PO}_{4}\right)_{2}$. However, the experiment was conducted at $\mathrm{pH} 9$; thus, large amounts of $\mathrm{Zn}_{3}\left(\mathrm{PO}_{4}\right)_{2}$ began to dissolve and precipitate in the form of $\mathrm{Zn}(\mathrm{OH})_{2}$. These chemical reactions both increased the phosphate content and consumed $\mathrm{OH}^{-}$in the solution, thus inhibiting HAP crystallization for P removal.

\subsection{Effects of Metal Ions on the Characteristics of Crystallized Products}

The inhibitory effects of metal ions on the crystallization processes are commonly accompanied by irregular crystal growth, because the adsorption of such ions onto crystal surfaces is not uniform [25]. The XRD patterns of the HAP crystals obtained in the presence of metal ions at different concentrations are shown in Figure 5. All the patterns matched well with the data from the HAP standard powder diffraction database at the International Centre for Diffraction Data (PDF\#73-0293). XRD showed that HAP formation was poorly crystalline, mainly due to its small crystallite size and the generation of amorphous Ca phosphate (ACP, OCP, and DCPD) [10,31,32]. It can be inferred that the foreign metal 
ions were adsorbed onto the surface of the developing crystals and were thus incorporated into the crystal structure, leading to a poor XRD pattern.

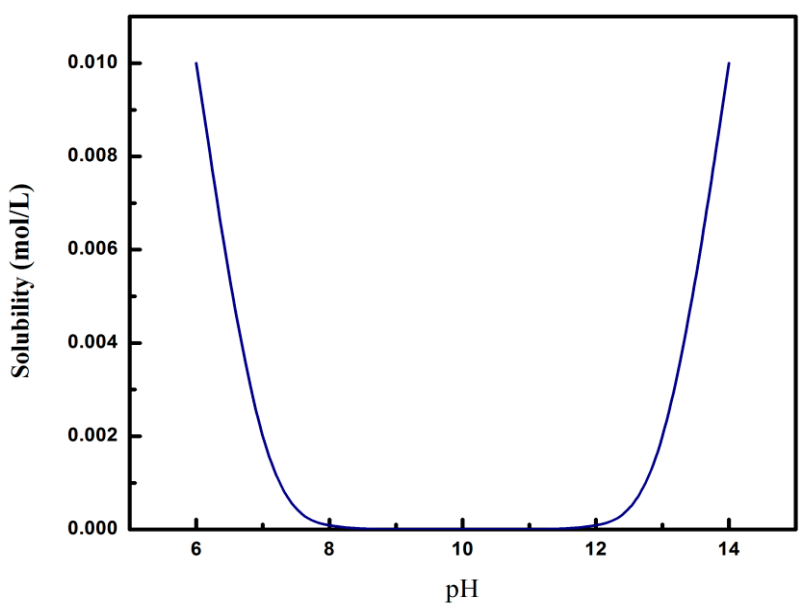

Figure 4. The relation between the solubility of $\mathrm{Zn}(\mathrm{OH})_{2}$ and $\mathrm{pH}$.
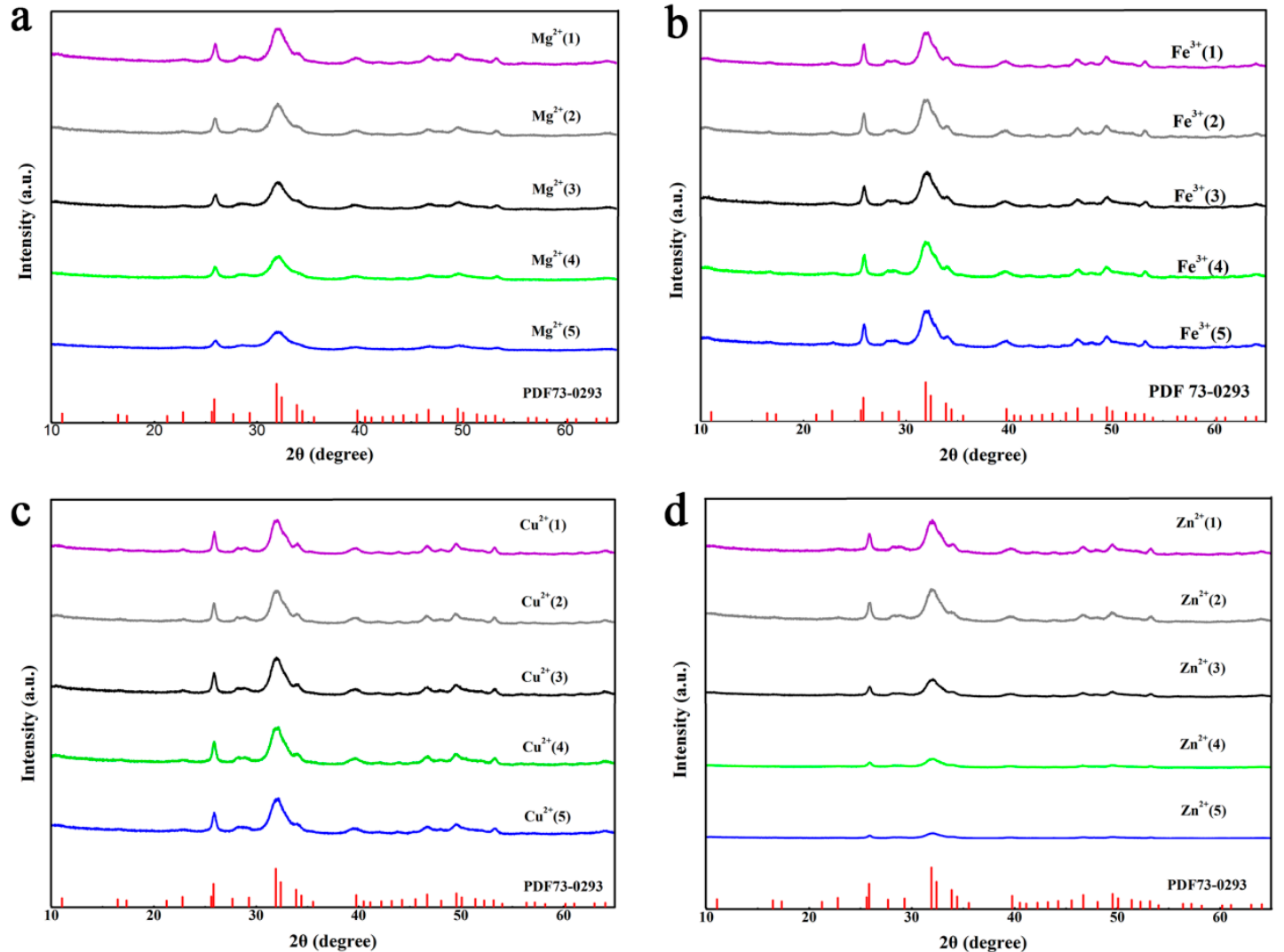

Figure 5. The effects of different concentrations of metal ions on the X-ray diffraction diagrams of HAP crystallized products. (a) $\mathrm{Mg}^{2+} ;$ (b) $\mathrm{Fe}^{3+} ;$ (c) $\mathrm{Cu}^{2+} ;$ (d) $\mathrm{Zn}^{2+}$. The dosages of the metal ions were 5, 10, 15,20 , and $25 \mathrm{mg} / \mathrm{L}$, which correspond to serial numbers $1,2,3,4$, and 5 , respectively.

The SEM and their associated EDS patterns of the HAP crystals obtained in the presence of several metal ions are shown in Figure 6. The SEM images of the HAP standard shows the typical HAP crystal shape, which is a finely distributed crystalline substance (Figure 6a), which were closely matched with those reported by earlier researchers [3,10,33,34]. To comprehensively evaluate the effects of metal ions on the characteristics of HAP crystallized products, the SEM-EDS images shown in Figure $6 c-j$ in the 
presence of metal ions at a concentration of $25 \mathrm{mg} / \mathrm{L}$ were selected to represent the variations in HAP morphology and composition.

a

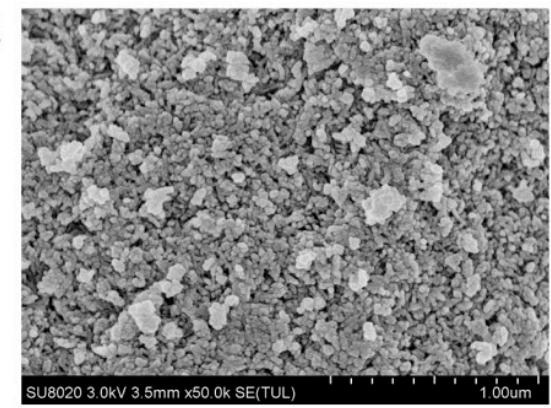

C

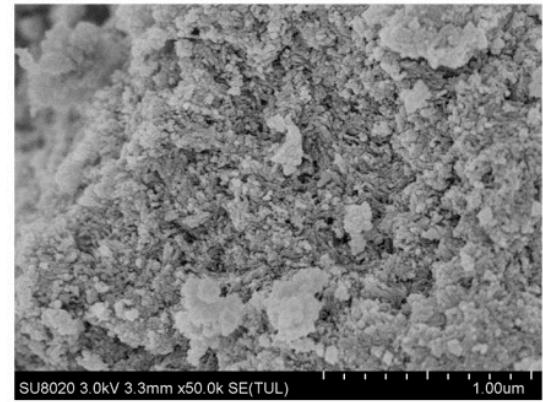

e

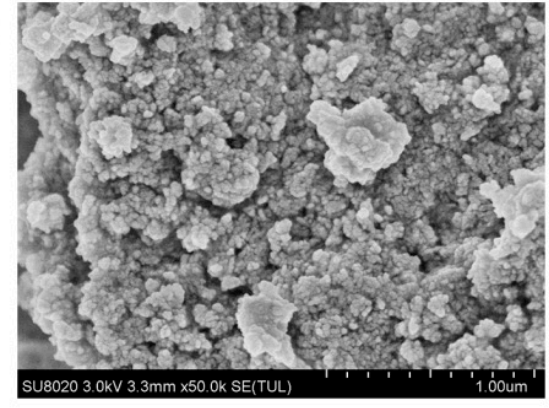

$\mathrm{g}$

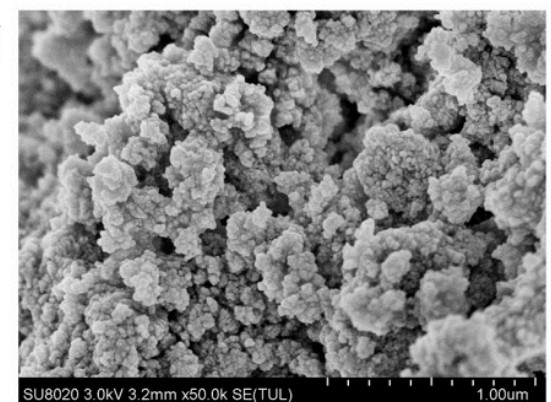

i

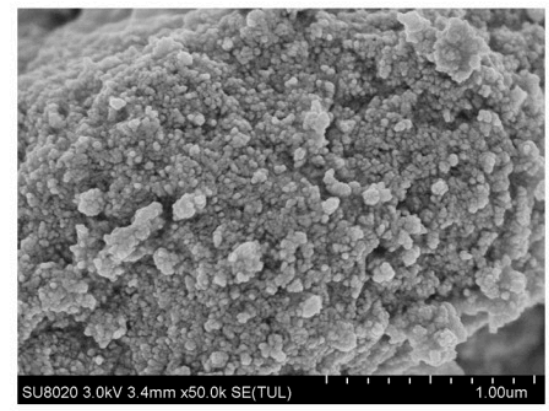

b
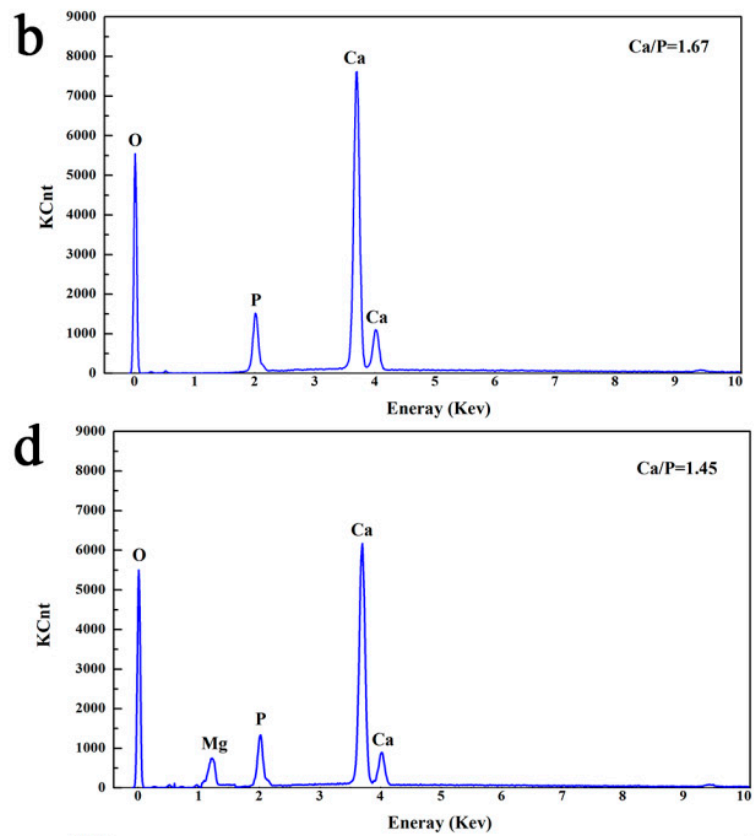

$\mathrm{f}$

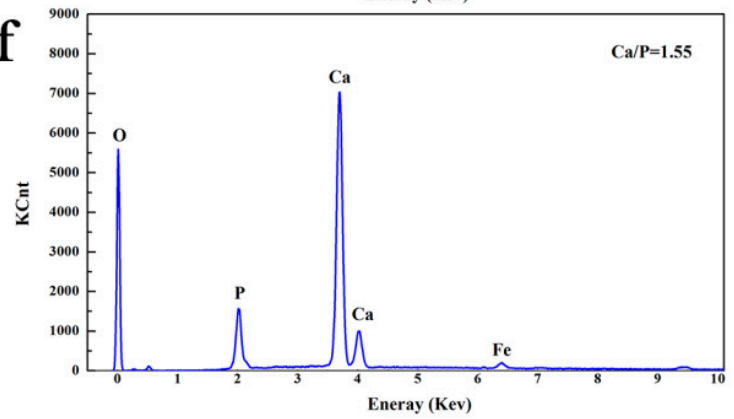

h

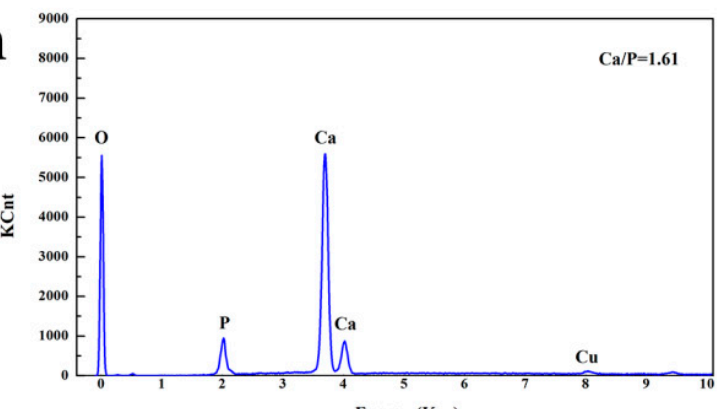

j

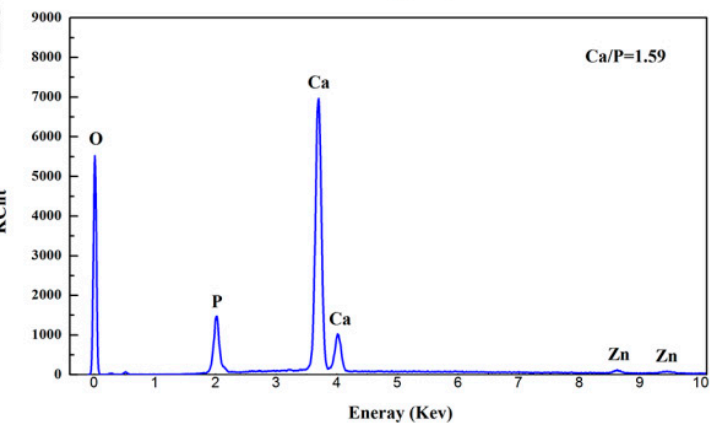

Figure 6. The effects of metal ions on the SEM-EDS of HAP crystallized products (the dosages of the metal ions were $25 \mathrm{mg} / \mathrm{L}) .(\mathbf{a}, \mathbf{b})$ blank sample; (c,d) $\mathrm{Mg}^{2+} ;(\mathbf{e}, \mathbf{f}) \mathrm{Fe}^{3+} ;(\mathbf{g}, \mathbf{h}) \mathrm{Cu}^{2+} ;(\mathbf{i}, \mathbf{j}) \mathrm{Zn}^{2+}$. 
XRD patterns in Figure 5a showed that HAP was the most clearly detectable phase for precipitates in the presence of $\mathrm{Mg}^{2+}$. The typical intensity of the HAP peak decreased as the $\mathrm{Mg}^{2+}$ concentration increased. The SEM diagram in Figure $6 c$ shows that the particle size of HAP crystals decreased, and a small number of needle-like crystals appeared, at an $\mathrm{Mg}^{2+}$ concentration of $25 \mathrm{mg} / \mathrm{L}$, indicating that a small amount of struvite crystals formed in the reaction system due to the presence of $\mathrm{Mg}^{2+}$. The elemental composition of the crystal products was quantitatively analyzed using EDS (Figure 6d) and showed that oxygen $(\mathrm{O}), \mathrm{Ca}$, and $\mathrm{P}$ were the main elements in the samples, and that the $\mathrm{Ca} / \mathrm{P}$ ratio was lower than the theoretical value for $\operatorname{HAP}(1.67)$, indicating that the crystalline products contained amorphous Ca phosphate. The low level of Mg in the EDS spectrum suggested MAP co-precipitation with amorphous Ca phosphate. Although the existence of $\mathrm{Mg}^{2+}$ reduced the purity of HAP crystals, it increased the $\mathrm{P}$ removal rate in the system.

The presence of $\mathrm{Fe}^{3+}$ and $\mathrm{Cu}^{2+}$ did not significantly affect the crystal structure of $\mathrm{HAP}$ (Figure $5 \mathrm{~b}, \mathrm{c}$ ), because $\mathrm{Fe}^{3+}$ and $\mathrm{Cu}^{2+}$ readily formed low-solubility hydroxyl metal compounds in the alkaline solution. However, $\mathrm{Fe}^{3+}$ greatly reduced the concentration of phosphate in the solution, mainly due to precipitation of Fe phosphate, resulting in a decrease in HAP production. This result indicates that $\mathrm{Fe}^{3+}$ is an effective inhibitor of HAP crystallization because of its stronger ability to bind to phosphate than that of $\mathrm{Ca}^{2+}$ [21]. Luedecke et al. [35] proposed a chemical model to describe the precipitation of ferric hydroxyphosphate by combining phosphate with ferric hydroxide in activated sludge, and found that ferric hydroxyphosphate deposits can be represented by the empirical formula $\mathrm{Fe}_{2.5} \mathrm{PO}_{4}(\mathrm{OH})_{4.5}$ with a solubility product constant of 96.7; the corresponding solubility constant for HAP was 58.69. The addition of a small amount of $\mathrm{Fe}^{3+}$ had a slight effect on the amount of HAP produced, resulting in an increase in the size of the amorphous crystalline products and a roughening of the structure; this result agreed with those shown in Figure 6e. Compared with $\mathrm{Fe}^{3+}, \mathrm{Cu}^{2+}$ had a similar effect on HAP crystal morphology. The quantitative analysis of EDS elements showed that in the presence of $\mathrm{Fe}^{3+}$ and $\mathrm{Cu}^{2+}$, low levels of $\mathrm{Fe}$ and $\mathrm{Cu}$, respectively, were found in the crystalline products, confirming the presence of $\mathrm{Fe}$ and $\mathrm{Cu}$ salts in addition to Ca phosphate. However, the low level of metal salt ions had no significant effect on the HAP crystal structure.

As shown in Figure $5 d$, there was strong background interference from $\mathrm{Zn}^{2+}$ on the XRD spectrum of HAP, suggesting that the crystallized products contained a mixture of several amorphous substances. When the $\mathrm{Zn}^{2+}$ concentration exceeded $20 \mathrm{mg} / \mathrm{L}$, there was almost no obvious HAP crystalline peak. Milky white flocculent precipitates observed during the reaction process suggested that $\mathrm{Zn}(\mathrm{OH})_{2}$ and $\mathrm{Ca}(\mathrm{OH})_{2}$ precipitates had formed in the solution and flocculated with other precipitates, resulting in a mixture of HAP and a variety of amorphous $\mathrm{Ca}$ and $\mathrm{Zn}$ salts, preventing clear characteristic peaks on XRD. SEM images of HAP under the influence of $\mathrm{Zn}^{2+}$ are shown in Figure 6i. The crystalline products exhibited smooth surfaces and dense bulk structures at high $\mathrm{Zn}^{2+}$ concentrations, possibly due to a cover of amorphous precursors. As discussed previously, ion impurities are adsorbed onto crystal surfaces, resulting in an energy barrier to crystallization [36]. Compared with the presence of no ion impurities, nucleation requires a greater impetus for crystallization, since a higher energy barrier must be overcome for crystal growth at high concentrations of ion impurities [10].

\section{Conclusions}

(1) The $\mathrm{Ca} / \mathrm{P}$ ratio and $\mathrm{pH}$ were found to be key factors affecting the $\mathrm{P}$ removal rate by HAP crystallization. A rapid increase in the $\mathrm{P}$ removal efficiency occurred at $\mathrm{pH} 8-10$, with significant increases in crystallinity and $\mathrm{P}$ removal. Higher $\mathrm{pH}$ values reversed the reduction in $\mathrm{P}$ removal due to the enhanced precipitation effect of $\mathrm{CaCO}_{3}$ and $\mathrm{Ca}(\mathrm{OH})_{2}$. In contrast, the theoretical $\mathrm{Ca} / \mathrm{P}$ ratio for HAP is 1.67, and the excessive Ca concentration in the solution did not significantly increase the $\mathrm{P}$ removal efficiency. $\mathrm{CaCO}_{3}$ precipitation occurred after adding high concentrations of $\mathrm{Ca}^{2+}$ to the alkaline environment, which can easily cause $\mathrm{Ca}^{2+}$ loss and a waste of chemicals.

(2) The addition of $\mathrm{Mg}^{2+}$ and $\mathrm{Fe}^{3+}$ reduced the crystalline purity of HAP to some extent but also improved the phosphate removal rate due to the co-precipitation of metal phosphate and HAP. In the 
presence of $\mathrm{Mg}^{2+}$, a small amount of needle-like crystals appeared on the surface of the crystalline products due to the formation of small amounts of MAP crystallization products. The addition of $\mathrm{Fe}^{3+}$ and $\mathrm{Cu}^{2+}$ had no significant effect on the HAP structure because $\mathrm{Fe}^{3+}$ and $\mathrm{Cu}^{2+}$ readily formed low-solubility hydroxyl metal compounds in the alkaline solution; these are rarely involved in HAP crystallization. There was strong background interference of $\mathrm{Zn}^{2+}$ on the XRD spectra of HAP, indicating that the crystallized products may contain a mixture of several amorphous substances. The crystalline products captured on the SEM images at high $\mathrm{Zn}^{2+}$ concentrations had smooth surfaces and dense bulk structures, perhaps due to a cover of amorphous precursors.

Author Contributions: The research presented here was carried out as a collaboration between all the authors. H.D. conceived and designed the experiments; X.T. processed the data and carried out the statistical analysis of the results; T.S., H.Z., and X.W. provided suggestions on the methodology and structure of the manuscript.

Funding: This research was funded by the Social Development Project of Zhenjiang [Grant No. 2016014], the Qing Lan Project for Young Core Teachers in University of Jiangsu Province, China, the Natural Science Foundation of Jiangsu Province of China [Grant No. BK2012272], and the Natural Science Foundation of China [Grant No. 31400448].

Acknowledgments: We are very grateful to the editor and three anonymous reviewers for their valuable comments and constructive suggestions that helped us to greatly improve the manuscript.

Conflicts of Interest: The authors declare no conflict of interest.

\section{References}

1. Shepherd, J.G.; Sohi, S.P.; Heal, K.V. Optimizing the recovery and reuse of phosphorus from wastewater effluent for sustainable fertilizer development. Water Res. 2016, 94, 155-165. [CrossRef] [PubMed]

2. Conley, D.J.; Paerl, H.W.; Howarth, R.W.; Boesch, D.F.; Seitzinger, S.P.; Havens, K.E.; Lancelot, C.; Likens, G.E. Controlling eutrophication: Nitrogen and phosphorus. Science 2009, 323, 1014-1015. [CrossRef] [PubMed]

3. Dai, H.; Lu, X.; Peng, Y.; Yang, Z.; Zhu, H. Effects of supersaturation control strategies on hydroxyapatite (HAP) crystallization for phosphorus recovery from wastewater. Environ. Sci. Pollut. Res. 2017, 24, 1-9. [CrossRef] [PubMed]

4. Mayer, B.K.; Baker, L.A.; Boyer, T.H.; Drechsel, P.; Gifford, M.; Hanjra, M.A.; Parameswaran, P.; Stoltzfus, J.; Westerhoff, P.; Rittmann, B.E. Total value of phosphorus recovery. Environ. Sci. Technol. 2016, 50, 6606-6620. [CrossRef] [PubMed]

5. Fang, L.; Li, J.S.; Guo, M.Z.; Cheeseman, C.R.; Tsang, D.C.; Donatello, S.; Poon, C.S. Phosphorus recovery and leaching of trace elements from incinerated sewage sludge ash (ISSA). Chemosphere 2018, 193, $278-287$. [CrossRef] [PubMed]

6. Cieślik, B.; Konieczka, P. A review of phosphorus recovery methods at various steps of wastewater treatment and sewage sludge management. The concept of "no solid waste generation" and analytical methods. J. Clean. Prod. 2017, 142, 1728-1740. [CrossRef]

7. Yuan, Z.; Pratt, S.; Batstone, D.J. Phosphorus recovery from wastewater through microbial processes. Curr. Opin. Biotechnol. 2012, 23, 878-883. [CrossRef] [PubMed]

8. De-Bashan, L.E.; Bashan, Y. Recent advances in removing phosphorus from wastewater and its future use as fertilizer (1997-2003). Water Res. 2004, 38, 4222-4246. [CrossRef] [PubMed]

9. Qiu, G.; Law, Y.M.; Das, S.; Ting, Y.P. Direct and complete phosphorus recovery from municipal wastewater using a hybrid microfiltration-forward osmosis membrane bioreactor process with seawater brine as draw solution. Environ. Sci. Technol. 2015, 49, 6156-6163. [CrossRef] [PubMed]

10. Dai, H.; Lu, X.; Peng, Y.; Zou, H.; Jing, S. An efficient approach for phosphorus recovery from wastewater using series-coupled air-agitated crystallization reactors. Chemosphere 2016, 165, 211-220. [CrossRef] [PubMed]

11. Okano, K.; Uemoto, M.; Kagami, J.; Miura, K.; Aketo, T.; Toda, M.; Honda, K.; Ohtake, H. Novel technique for phosphorus recovery from aqueous solutions using amorphous calcium silicate hydrates (A-CSHs). Water Res. 2013, 47, 2251-2259. [CrossRef] [PubMed]

12. Egle, L.; Rechberger, H.; Krampe, J.; Zessner, M. Phosphorus recovery from municipal wastewater: An integrated comparative technological, environmental and economic assessment of $\mathrm{p}$ recovery technologies. Sci. Total Environ. 2016, 571, 522-542. [CrossRef] [PubMed] 
13. Güney, K.; Weidelener, A.; Krampe, J. Phosphorus recovery from digested sewage sludge as MAP by the help of metal ion separation. Water Res. 2008, 42, 4692-4698. [CrossRef] [PubMed]

14. Song, Y.; Dai, Y.; Hu, Q.; Yu, X.; Qian, F. Effects of three kinds of organic acids on phosphorus recovery by magnesium ammonium phosphate (MAP) crystallization from synthetic swine wastewater. Chemosphere 2014, 101, 41-48. [CrossRef] [PubMed]

15. Corre, K.S.L.; Valsamijones, E.; Hobbs, P.; Parsons, S.A. Phosphorus recovery from wastewater by struvite crystallization: A review. Crit. Rev. Environ. Sci. Technol. 2009, 39, 433-477. [CrossRef]

16. Pastor, L.; Marti, N.; Bouzas, A.; Seco, A. Sewage sludge management for phosphorus recovery as struvite in EBPR wastewater treatment plants. Bioresour. Technol. 2008, 99, 4817-4824. [CrossRef] [PubMed]

17. Kataki, S.; West, H.; Clarke, M.; Baruah, D.C. Phosphorus recovery as struvite: Recent concerns for use of seed, alternative Mg source, nitrogen conservation and fertilizer potential. Resour. Conserv. Recycl. 2016, 107, 142-156. [CrossRef]

18. Kumar, R.; Prakash, K.H.; Cheang, P.; Khor, K.A. Temperature driven morphological changes of chemically precipitated hydroxyapatite nanoparticles. Langmuir 2004, 20, 5196-5200. [CrossRef] [PubMed]

19. Song, Y.H.; Weidler, P.G.; Berg, U.; Nüesch, R.; Donnert, D. Calcite-seeded crystallization of calcium phosphate for phosphorus recovery. Chemosphere 2006, 63, 236-243. [CrossRef] [PubMed]

20. Gong, J.; Liu, Y.; Sun, $\mathrm{X} . \mathrm{O}_{3}$ and $\mathrm{UV} / \mathrm{O}_{3}$ oxidation of organic constituents of biotreated municipal wastewater. Water Res. 2008, 42, 1238-1244. [CrossRef] [PubMed]

21. Yan, H.; Shih, K. Effects of calcium and ferric ions on struvite precipitation: A new assessment based on quantitative X-ray diffraction analysis. Water Res. 2016, 95, 310-318. [CrossRef] [PubMed]

22. Ottosen, L.M.; Kirkelund, G.M.; Jensen, P.E. Extracting phosphorous from incinerated sewage sludge ash rich in iron or aluminum. Chemosphere 2013, 91, 963-969. [CrossRef] [PubMed]

23. Li, R.; Zhao, W.; Li, Y.; Wang, W.; Zhu, X. Heavy metal removal and speciation transformation through the calcination treatment of phosphorus-enriched sewage sludge ash. J. Hazard. Mater. 2015, 283, 423-431. [CrossRef] [PubMed]

24. Madsen, H.E.L. Influence of foreign metal ions on crystal growth and morphology of brushite $\left(\mathrm{CaHPO}_{4} \cdot 2 \mathrm{H}_{2} \mathrm{O}\right)$ and its transformation to octacalcium phosphate and apatite. J. Cryst. Growth 2008, 310, 2602-2612. [CrossRef]

25. Muryanto, S.; Bayuseno, A. Influence of $\mathrm{Cu}^{2+}$ and $\mathrm{Zn}^{2+}$ as additives on crystallization kinetics and morphology of struvite. Powder Technol. 2014, 253, 602-607. [CrossRef]

26. Dai, H.; Lu, X.; Peng, Y.; Yang, Z.; Zhu, H. Characteristics of metastable zone in the crystallization process: A case study of sparingly soluble hydroxyapatite. Desalin. Water Treat. 2017, 62, 192-199. [CrossRef]

27. APHA. Standard Methods for the Examination of Water $\&$ Wastewater, 21st ed.; American Public Health Association, American Water Works Association and Water Environment Federation: Washington, DC, USA, 2005.

28. Monballiu, A.; Desmidt, E.; Ghyselbrecht, K.; Meesschaert, B. Phosphate recovery as hydroxyapatite from nitrified UASB effluent at neutral $\mathrm{pH}$ in a CSTR. J. Environ. Chem. Eng. 2018, 6, 4413-4422. [CrossRef]

29. Kabdaszli, I.; Parsons, S.A.; Tünaya, O. Effect of major ions on induction time of struvite precipitation. Croat. Chem. Acta 2006, 9, 243-251.

30. Zheng, X.; Sun, P.; Lou, J.; Fang, Z.; Guo, M.; Song, Y.; Tang, X.; Jiang, T. The long-term effect of nitrite on the granule-based enhanced biological phosphorus removal system and the reversibility. Bioresour. Technol. 2013, 132, 333-341. [CrossRef] [PubMed]

31. Harris, W.G.; Wilkie, A.C.; Cao, X.; Sirengo, R. Bench-scale recovery of phosphorus from flushed dairy manure wastewater. Bioresour. Technol. 2008, 99, 3036-3043. [CrossRef] [PubMed]

32. Combes, C.; Rey, C. Amorphous calcium phosphates: Synthesis, properties anduses in biomaterials. Acta Biomater. 2010, 6, 3362-3378. [CrossRef] [PubMed]

33. Karapinar, N.; Hoffmann, E.; Hahn, H.H. P-recovery by secondary nucleation and growth of calcium phosphates on magnetite mineral. Water Res. 2006, 40, 1210-1216. [CrossRef] [PubMed]

34. Hosni, K.; Moussa, S.B.; Chachi, A.; Amor, M.B. The removal of $\mathrm{PO}_{4}{ }^{3-}$, by calcium hydroxide from synthetic wastewater: Optimisation of the operating conditions. Desalination 2008, 223, 337-343. [CrossRef]

35. Luedecke, C.; Hermanowicz, S.W.; Jenkins, D. Precipitation of ferric phosphate in activated sludge: A chemical model and its verification. Water Sci. Technol. 1989, 21, 325-337. [CrossRef] 
36. Sangwal, K.; Mielniczek-Brzóska, E. Effect of impurities on metastable zone width for the growth of ammonium oxalate monohydrate crystals from aqueous solutions. J. Cryst. Growth 2004, 267, 662-675. [CrossRef]

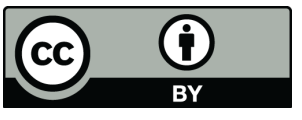

(c) 2018 by the authors. Licensee MDPI, Basel, Switzerland. This article is an open access article distributed under the terms and conditions of the Creative Commons Attribution (CC BY) license (http:/ / creativecommons.org/licenses/by/4.0/). 